\title{
Prolongation of Survival of Rat Cardiac Allografts by T Cell Vaccination
}

Oz M. Shapira, * Eitan Mor, * Tamara Reshef, ${ }^{*}$ Reuven A. Pfeffermann, * and Irun R. Cohen*

${ }^{\ddagger}$ The Department of Cell Biology, Weizmann Institute of Science, * Department of Surgery 'B, 'and Kaplan Hospital, Rehovot 76100, Israel

\begin{abstract}
Administration of attenuated, activated autoimmune T lymphocytes to syngeneic mice and rats has been shown to prevent or induce remission of experimental autoimmune diseases specific for the autoimmune $T$ cells. The process has been termed " $T$ cell vaccination." In a recent study, $T$ cell vaccination was done using $\mathbf{T}$ cells sensitized to rat alloantigens. The procedure produced a significant reduction of the mixed lymphocyte reaction (MLR) against allogeneic cells. The reduction in MLR was not specific: Vaccination with $T$ cells specific for stimulator cells of one allotype led to a reduced MLR stimulated by cells of another allotype. The present study was undertaken to examine whether $\mathbf{T}$ cell vaccination can induce tolerance to transplantation antigens in vivo. We used the model of heterotopic cardiac transplantation in rats. We now report that vaccinating rats with syngeneic, activated, alloantigen-primed $T$ lymphocytes significantly prolonged survival of rat cardiac allografts. The effect of $T$ cell vaccination was most evident when the $T$ cells had been obtained from rats specifically sensitized against the donor rats: Brown-Norway (BN) allografts in control Wistar rats survived $8.5 \pm 0.4 \mathrm{~d}$ while $\mathrm{BN}$ allografts survived $29.2 \pm 7.1$ $d$ in Wistar rats that had been vaccinated with Wistar anti-BN cells. Vaccination of Wistar rats with Wistar anti-hooded $T$ cells prolonged survival of BN heart allografts to a lesser but significant degree (13.0 $\pm 1.1 \mathrm{~d})$. Thus, $T$ cell vaccination of recipients can prolong survival of allografts. (J. Clin. Invest. 1993. 91:388-390.) Key words: autoimmune diseases $\bullet T$ cell vaccination • antiidiotypic • antiergotypic • cardiac transplantation
\end{abstract}

\section{Introduction}

Resistance to a variety of experimental autoimmune diseases in mice and rats can be induced by treating animals with chemically or physically attenuated $\mathrm{T}$ lymphocytes that have been specifically activated against the target antigen, a modality termed "T cell vaccination" (1-5).

$T$ cell vaccination induces the activation of $T$ helper and $T$ suppressor cells of two types: antiidiotypic $T$ cells directed to the specific $T$ cell vaccine $(5,6)$, and $T$ cells reactive to $T$ cell activation markers, the antiergotypic response (7). Both mechanisms combine to regulate autoimmunity. The results with $T$ cell vaccination in autoimmune diseases led us to evaluate its efficacy in controlling $\mathrm{T}$ cell responses to alloantigens; indeed,

Address correspondence and reprint requests to Dr. I. R. Cohen, Department of Cell Biology, The Weizmann Institute of Science, Rehovot 76100, Israel.

Received for publication 19 February 1992 and in revised form 13 July 1992.

J. Clin. Invest.

(C) The American Society for Clinical Investigation, Inc. $0021-9738 / 93 / 02 / 0388 / 03 \quad \$ 2.00$

Volume 91, February 1993, 388-390 it was found that $T$ cell vaccination was effective in inhibiting one-way mixed lymphocyte reaction (MLR) ${ }^{1}$ in vitro (8).

The aim of the present study was to examine the effect of $T$ cell vaccination on an alloantigen response in vivo. We used the model of heterotopic cardiac transplantation in rats. Wistar rats were vaccinated with attenuated $T$ cell vaccines from Wistar rats that had been sensitized against BN alloantigens. Control $\mathrm{T}$ cell vaccines were made from mitogen-activated Wistar $T$ cells, or from Wistar $T$ cells sensitized against third party hooded (Ho) rats. The Wistar rats were then grafted with Brown-Norway (BN) hearts.

We found that allospecific $T$ cell vaccination with no other treatment produced a greater than threefold increase in the mean survival of the heart allografts. However, vaccination with $\mathrm{T}$ cells primed to third party alloantigens also inhibited rejection to a significant degree.

\section{Methods}

Animals. Cardiac transplantation was performed between male inbred Wistar rats $\left(\mathrm{RT}^{\mathrm{w}}{ }^{\mathrm{w}}\right.$ ) weighing 350-500 g serving as recipients and male inbred $B N$ rats $\left(R T 1^{n}\right)$ weighing $250-350 \mathrm{~g}$ serving as donors. Male inbred Ho rats $\left(R T 1^{c}\right)$ were used to produce third party $T$ cell vaccines. All rats were obtained from The Animal Breeding Center, Weizmann Institute of Science.

Skin allografting. Full thickness skin grafting was performed as previously described (9). One male rat served as a donor to up to 10 male recipients. Day of grafting was day 0 . The day of rejection was defined as the day on which complete separation of the graft occurred.

Cardiac transplantation. Heterotopic cardiac transplantation was performed under pentobarbital anesthesia $(50 \mathrm{mg} / \mathrm{kg}$ intraperitoneally), using the modified technique of Ono and Lindsey (10). Day of grafting was day 0 . Graft survival was assessed by daily palpation. The day of rejection was defined as the day of cessation of heartbeat. Rejection was confirmed histologically. Technical failures within the first 72 $\mathrm{h}$ were excluded from the experimental groups.

$T$ cell vaccination. Wistar rats were primed by transplanting $\mathrm{BN}$ or Ho skin grafts into the neck region. When the skin allografts were rejected, the draining cervical and axillary lymph nodes were excised and the lymphocytes were stimulated by culture for $48 \mathrm{~h}$ with 1.25 $\mu \mathrm{g} / \mathrm{ml}$ concanavalin $\mathrm{A}$ (Con $\mathrm{A}$ ) in medium containing antibiotics, 2-mercaptoethanol, and $1 \%$ autologous serum as described (11). It was previously demonstrated that activation of $\mathrm{T}$ cells with Con $\mathrm{A}$ in vitro led to a substantial increase in the activity and frequency of $T$ cells specific for antigens to which the rats had been sensitized in vivo (12). Lymph nodes from naive Wistar rats activated with Con A in the same manner served as controls to differentiate between antiergotypic and antiidiotypic responses (7).

The Wistar anti-BN-, Wistar anti-Ho-, and Con A-activated Wistar lymphocytes were attenuated by treatment for 15 min with $0.3 \%$ glutaraldehyde and then washed three times in PBS as described (4). Wistar rats were vaccinated with three intraperitoneal injections of 2 $\times 10^{7}$ vaccinating cells, performed on days $-14,-7$, and +5 of cardiac transplantation. A fourth vaccination was done on day +12 , when grafts survived that long. In an alternative protocol, instead of skin allografting, Wistar rats were primed by intraperitoneal injection of 5 $\times 10^{6} \mathrm{BN}$ splenocytes. Mesenteric, cervical, and axillary LN were ex-

1. Abbreviations used in this paper: $\mathrm{BN}, \mathrm{Brown}-\mathrm{Norway}$; Con A, concanavalin A; Ho, hooded; MLR, mixed lymphocyte reaction; TcR, T cell receptor. 
cised 2 wk later, and the vaccinating lymphocytes were prepared as described above.

Statistics. The Kaplan-Meier method was used to compute actuarial graft survival. The data obtained in each group were expressed as means \pm SEM, and the Mann-Whitney $U$ test was used for calculation of intergroup significant differences.

\section{Results}

Wistar, Brown-Norway, and Hooded rats mutually reject skin grafts. The rat strains in this study were inbred and were derived from standard strains known to be allogenic at the major histocompatibility complex. Nevertheless, we performed skin grafting to confirm the histoincompatibility of the rats. Table I shows that Wistar rats rejected BN skin grafts within $16.4 \pm 1.5$ $\mathrm{d}$ and Ho skin grafts within $13.5 \pm 1.1 \mathrm{~d}$. BN rejected Ho skin grafts within $13.7 \pm 0.1 \mathrm{~d}$. Although it appears that $B N$ skin grafts survived in Wistar rats slightly longer than Ho grafts, the differences did not reach statistical significance. Thus, we may conclude that each of the three strains differs substantially from the other two in their major histocompatibility loci.

$T$ cell vaccination prolongs cardiac allograft survival. The results of heart transplantation are shown in Table II and Fig. 1. Untreated Wistar rats rejected BN cardiac allografts within $8.5 \pm 0.4 \mathrm{~d}$ (group 1). Vaccination of those rats with Wistar anti-BN cells (group 2) primed by skin allografts significantly prolonged cardiac allograft survival to $29.2 \pm 7.1 \mathrm{~d}$ ( $P$ $<0.0001)$. Priming of the vaccine donor by BN splenocytes (group 3 ) appeared to be less effective than priming by skin grafting: Survival of cardiac allografts was $18.0 \pm 0.34 \mathrm{~d}$; however, this difference was not statistically significant.

Cardiac allograft survival is not influenced by an antiergotype response. As an antiergotypic control, we vaccinated Wistar rats with Con A-activated, syngeneic $\mathrm{T}$ cells obtained from naive rats. It was previously shown that such a vaccination can successfully inhibit experimental autoimmune encephalomyelitis in rats by induction of an MHC-non-restricted antiergotypic response (7). In the present study this type of vaccination was followed by graft survival of $8.7 \pm 0.2 \mathrm{~d}$, virtually identical to the control group (Table II, group 4, Fig. 1). Thus, the prolongation of cardiac allograft survival achieved by $T$ cell vaccination was not likely caused by the induction of an antiergotypic response to activation markers on syngeneic $T$ cells.

The effect of $T$ cell vaccination is not MHC-restricted. To examine the antigen specificity of $T$ cell vaccination, Wistar rats were vaccinated with Wistar anti-Ho cells and then transplanted with BN cardiac allografts. The BN heart grafts survived $13.1 \pm 0.1 \mathrm{~d}$ in these Wistar rats. This degree of survival

Table I. Survival of Wistar, BN, and Ho Skin Allografts

\begin{tabular}{ccccc}
\hline Group & Recipient & Donor & Graft survival & Mean \pm SEM \\
\hline 1 & Wistar & BN & $9,13,13,15,15$, & $16.4 \pm 1.5$ \\
& & & $17,17,19,20$, & \\
& & & 26 & \\
2 & Wistar & Ho & $10,11,11,11,12$, & $13.5 \pm 1.1$ \\
& & & $13,14,14,18$, & \\
& & & 21 \\
3 & BN & Ho & $10,12,14,14,15$, & $13.7 \pm 0.1$ \\
& & & 17 & \\
\hline
\end{tabular}

Wistar and BN rats received skin grafts from BN or Ho donors. Rejection was scored as the day of separation of the skin graft. Differences between the groups were not statistically significant.
Table II. BN Cardiac Allograft Survival in Wistar Recipients Treated with $T$ Cell Vaccination

\begin{tabular}{ccccc}
\hline & $\begin{array}{c}\text { Wistar T cell } \\
\text { vaccine (mode of } \\
\text { priming) }\end{array}$ & Graft survival & Mean \pm SEM & $P$ values \\
\hline & & $d$ & & \\
1 & None & $7,7,8,8,8,8$, & $8.5 \pm 0.4$ & \\
& & $9,9,10,11$ & & \\
2 & Anti-BN & $18,19,21,24$, & $29.2 \pm 7.1$ & $<0.0001$ vs 1 \\
& & 29,64 & & NS vs 3 \\
3 & Anti-BN & $9,17,21,25$ & $18.0 \pm 3.4$ & 0.025 vs 1 \\
4 & Con A & $8,8,9,9,9,9$ & $8.7 \pm 0.2$ & NS vs 1 \\
5 & Anti-Ho & $8,12,14,14$, & $13.0 \pm 1.1$ & 0.01 vs 1 \\
& & 14,16 & & 0.001 vs 2 \\
& & & \\
\hline
\end{tabular}

Wistar rats were grafted with BN heart allografts. Some of the rats were treated by $T$ cell vaccination with Con A-activated Wistar $T$ cells obtained from rats that were unprimed (group 4), or that had been primed with BN skin grafts (group 2), BN splenocytes (group 3 ), or Ho skin grafts (group 5). Rejection of the allograft was determined by cessation of the heart beat.

was significantly greater than the 8.5-8.7 $\mathrm{d}$ observed in the control Wistar rats, those unvaccinated, or those vaccinated with syngeneic Con A-blasts $(P=0.01)$. Note, however, that vaccination with the graft-specific anti-BN cells was significantly more effective (group 2 vs group $5, P=0.001$ ). Thus, it appears that $T$ cell vaccination against the response to the Ho strain of rats is able to induce some slight degree of tolerance to the diverse allogeneic antigens of BN strain rats. But the bulk of the effect is relatively specific for the specific MHC type.

\section{Discussion}

The results of the experiments described here demonstrate that vaccination of rats with syngeneic $T$ cells that have been primed against the donor MHC antigens can induce tolerance manifested by a significant prolongation of cardiac allograft survival. This effect of $T$ cell vaccination was achieved without detectable side effects. Similar to the effect of T cell vaccination on the MLR in vitro (8), the effect was not entirely MHC restricted. Vaccination of Wistar rats using anti-Ho $T$ cells in-

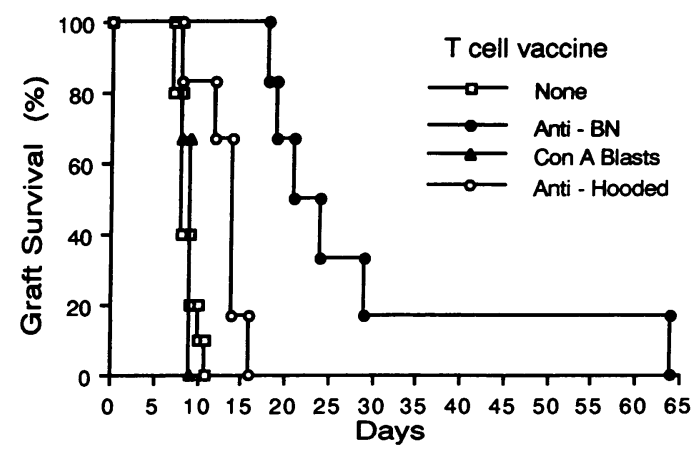

Figure 1. T cell vaccination prolongs survival of BN cardiac allografts in Wistar rats. BN hearts were grafted into Wistar rats, of which some had been treated by $T$ cell vaccination using syngeneic Wistar T cells primed to BN or Ho skin grafts. Some Wistar rats were vaccinated with Con A-activated blasts obtained from unprimed Wistar rats. Day of graft rejection was detected by cessation of the beat of the BN cardiac allograft. 
duced partial, but significant, tolerance to $\mathrm{BN}$ rat alloantigens. This lack of specificity cannot be attributed to an antiergotypic response induced by $T$ cell vaccination (7), as vaccination of animals with naive, syngeneic, Con $\mathrm{A}$-activated $\mathrm{T}$ cells had no detectable effect on allograft survival.

The mechanism by which $T$ cell vaccination inhibits the rejection of cardiac allografts remains to be determined. $T$ cell vaccination against autoimmune disease appears to involve the activation of regulatory $T$ cells that recognize the antigen receptors of the autoimmune $T$ cells $(5,6)$. Vandenbark and his associates have demonstrated that the effect of $T$ cell vaccination against autoimmune encephalomyelitis can be produced by vaccinating Lewis rats with a peptide from the $\mathrm{V} \beta$ segment of the $T$ cell receptor ( $T c R$ ) used by the autoimmune $T$ cells responsible for the disease (13). The effective $V \beta$ peptide was obtained from the CDR-II segment of the $\mathrm{V}$ gene, a segment of the $T c R$ common to all $T$ cells using that $V \beta$ family irrespective of their antigen specificity (13).

Indeed, Offner and her colleagues have shown that regulatory $T$ cells recognizing such a segment of the $T c R$ can inhibit $T$. cells that are reactive to an immunologically different epitope that happens to use a common $\mathrm{V} \beta$ gene (14). Thus, the partial inhibition of rejection of BN allografts brought about by an anti-Ho $T$ cell vaccine could be explained if the Wistar $T$ cells to $\mathrm{BN}$ and Ho alloantigens used TcR molecules with a similar $\mathrm{V} \beta$ segment. The questions of antiidiotypic regulation and of TcR usage will be more amenable to investigation once we have available the clones of $\mathrm{T}$ cells responsible for allograft rejection; at present we can only raise the questions.

Cross-reactivity between some histocompatibility epitopes of $\mathrm{BN}$ and Ho rats could also account for partial inhibition of rejection of $\mathrm{BN}$ allografts by $\mathrm{T}$ cell vaccination with Wistar anti-Ho cells. However, the histocompatibility epitopes of the rat are not at present well enough characterized to resolve this issue. Note that enhancement of survival of kidney allografts may be induced by pretransplant blood transfusion using a third party blood donor (15). The mechanisms of this effect are also unknown, but may be similar to the effect of $T$ cell vaccination.

Our interest in $\mathrm{T}$ cell vaccination in modulating the response to alloantigens stemmed from its successful application in a variety of experimental autoimmune diseases (1-5). Previously, Binz and Wigzell immunized mice and rats with antiMHC antibodies in CFA, or with purified MLR-activated T lymphoblasts in CFA $(16,17)$. They reported MHC-restricted reduction of MLR, cell mediated lymphotoxicity, graft versus host disease, and prolongation of skin allograft survival. They showed induction of antiidiotypic antibodies, as well as autoantiidiotypic killer and suppressor T cells $(19,20)$. The present study has extended $\mathrm{T}$ cell vaccination to cardiac allotransplantation as a model of a vascularized graft. The major difference between our results here and in the MLR (8), and those reported by Binz and Wigzell concern the degree of specificity: In contrast to the nonspecific inhibition we observed, Binz and Wigzell reported no inhibitory effect on a third party allograft after their procedure (16-20). The difference in results might be because of the different reagents and methods used for vaccination: Binz and Wigzell used either antibodies or T cells generated by in vitro MLR and injected them in CFA (16-20); in contrast, we used the Con A-activated $T$ cells from in vivo primed rats, fixed with a chemical cross-linker, and administered without CFA or other adjuvants. These diverse forms of immunization may have triggered different regulatory mecha- nisms, resulting in diverse forms of alloantigen unresponsiveness.

Be that as it may, $\mathrm{T}$ cell vaccination seems to be an effective therapeutic tool in experimental organ transplantation. The clinical application of this approach remains to be explored.

\section{Acknowledgments}

We thank Mrs. Rivka Karakash for her assistance in some of the experiments. Dr. I. R. Cohen is the incumbent of the Mauerberger Chair of Immunology.

\section{References}

1. Ben-Nun, A., H. Wekerle, and I. R. Cohen. 1981. Vaccination against encephalomyelitis with $\mathrm{T}$-lymphocyte line cells reactive against myelin basic protein. Nature (Lond.). 292:60-61.

2. Maron, R., R. Zerubavel, A. Friedman, and I. R. Cohen. 1983. T lymphocyte line specific for thyroglobulin produces or vaccinates against autoimmune thyroiditis in mice. J. Immunol. 131:2316-2322.

3. Cohen, I. R. 1986. Regulation of autoimmune disease physiological and therapeutic. Immunol. Rev. 94:5-21.

4. Lider, O., N. Karin, M. Shinitzky, and I. R. Cohen. 1987. Therapeutic vaccination against adjuvant arthritis using autoimmune $\mathrm{T}$ cells treated with hydrostatic pressure. Proc. Natl. Acad. Sci. USA. 84:4577-4580.

5. Sun, D., Y. Qin, J. Chluba, J. T. Epplen, and H. Wekerle. 1988. Suppression of experimentally induced autoimmune encephalomyelitis by cytolytic T-T cell interactions. Nature (Lond.). 332:843-845.

6. Lider, O., T. Reshef, E. Beraud, A. Ben-Nun, and I. R. Cohen. 1988. Anti-idiotypic network induced by $T$ cell vaccination against experimental autoimmune encephalomyelitis. Science (Wash. DC). 239:181-183.

7. Lohse, A., F. Mor, N. Karin, and I. R. Cohen. 1989. Control of experimental autoimmune encephalomyelitis by $\mathrm{T}$ cells responding to activated $\mathrm{T}$ cells. Science (Wash. DC). 244:820-822.

8. Lohse, A., E. Mor, T. Reshef, K. H. Meyer zum Buschenfelde, and I. R. Cohen. 1990. Inhibition of the mixed lymphocyte reaction by $T$ cell vaccination. Eur. J. Immunol. 20:2521-2524.

9. Baharav, E., O. Lider, M. Margalit, and I. R. Cohen. 1986. A modified technique for experimental skin grafting. J. Immunol. Methods. 90:1413-144.

10. Ono, K., and E. Lindsey. 1969. Improved technique of heart transplantation. J. Thorac. Cardiovasc. Surg. 57:225-229.

11. Ben-Nun, A., H. Wekerle, and I. R. Cohen. 1981. The rapid isolation of clonable antigen-specific $\mathrm{T}$ lymphocyte lines capable of mediating autoimmune encephalomyelitis. Eur. J. Immunol. 11:195-199.

12. Mor, F., A. W. Lohse, N. Karin, and I. R. Cohen. 1990. Clinical modeling of $\mathrm{T}$ cell vaccination against autoimmune disease in rats. Selection of antigen-specific T cells using a mitogen. J. Clin. Invest. 85:1594-1598.

13. Vandenbark, A. A., G. Hashim, and H. Offner. 1989. Immunization with synthetic $\mathrm{T}$-cell receptor $\mathrm{V}$-region peptide protects against experimental autoimmune encephalomyelitis. Nature (Lond.). 341:541-544.

14. Offner, H., M. Vainiene, D. P. Gold, W. J. Morrison, R-Y. Wang, G. Hashim, and A. A. Vandenbark. 1991. Protection against experimental encephalomyelitis: idiotypic autoregulation induced by a non-encephalitogenic $T$ cell clone expressing a cross-reactive $T$ cell receptor V gene. J. Immunol. 146:41654172 .

15. Lagaaij, E. L., I. P. Hennemann, M. Ruigrok, M. W. de-Haan, G. G. Persijn, A. Termijtelen, G. F. Hendricks, W. Weimar, F. H. Class, and J. J. van-Rood. 1989. Effect of one-HLA-DR-antigen-matched and completely HLADR mismatched blood transfusions on survival of heart and kidney allografts. $N$. Engl. J. Med. 321:701-705.

16. Binz, H., and H. Wigzell. 1976. Specific transplantation tolerance induced by autoimmunization against the individual's own, naturally occurring idiotypic, antigen-binding receptors. J. Exp. Med. 144:1438-1456.

17. Binz, H., and H. Wigzell. 1976. Successful induction of specific tolerance to transplantation antigens using autoimmunization against the recipient's own natural antibodies. Nature (Lond.). 262:294-295.

18. Anderson, L. C., H. Binz, and H. Wigzell. 1976. Specific unresponsiveness to transplantation antigens induced by autoimmunization with syngeneic, antigen-specific T lymphoblasts. Nature (Lond.). 264:778-780.

19. Andersson, L. C., M. Aguet, E. Wight, R. Andersson, H. Binz, and H. Wigzell. 1977. Induction of specific immune unresponsiveness using purified mixed leukocyte culture-activated $T$ lymphoblasts as autoimmunogen. I. Demonstration of general validity as to species and histocompatibility barriers. J. Exp. Med. 146:1124-1137.

20. Binz, H., and H. Wigzell. 1978. Induction of specific immune unresponsiveness using purified mixed leukocyte culture-activated $T$ lymphoblasts as autoimmunogen. III. Proof for the existence of autoanti-idiotypic killer T cells and transfer of suppression to normal syngeneic recipients by $\mathrm{T}$ or $\mathrm{B}$ lymphocytes. $J$. Exp. Med. 147:63-76. 